\title{
Phthalate esters contamination in soils and vegetables of plastic film greenhouses of suburb Nanjing, China and the potential human health risk
}

\author{
Ting Ting Ma ${ }^{1,2}$ - Long Hua Wu ${ }^{1} \cdot$ Like Chen $^{1,3}$ • Hai Bo Zhang ${ }^{1,4}$. \\ Ying Teng ${ }^{1}$ • Yong Ming Luo ${ }^{1,4}$
}

Received: 11 January 2015 / Accepted: 17 March 2015 / Published online: 15 April 2015

(C) Springer-Verlag Berlin Heidelberg 2015

\begin{abstract}
The contamination of phthalate esters (PAEs) has become a potential threat to the environment and human health because they could be easily released as plasticizers from the daily supply products, especially in polyethylene films. Concentration levels of total six PAEs, nominated as priority pollutants by the US Environmental Protection Agency (USEPA), were investigated in soils and vegetables from four greenhouse areas in suburbs of Nanjing, East China. Total PAEs concentration ranged from $930 \pm 840$ to $2450 \pm 710 \mu \mathrm{g} \mathrm{kg}^{-1}$ (dry weight (DW)) in soil and from $790 \pm 630$ to $3010 \pm 2130 \mu \mathrm{g} \mathrm{kg}^{-1}$ in vegetables. Higher concentrations of PAEs were found in soils except in Suo Shi (SS) area and in vegetables, especially in potherb mustard and purple tsai-tai samples. Risk assessment mainly based on the exposures of soil ingestion
\end{abstract}

Responsible editor: Leif Kronberg

Electronic supplementary material The online version of this article (doi:10.1007/s11356-015-4401-2) contains supplementary material, which is available to authorized users.

Yong Ming Luo

ymluo@yic.ac.cn

Key Laboratory of Soil Environment and Pollution Remediation, Institute of Soil Science, Chinese Academy of Sciences, Nanjing 210008, China

2 Institute of Hanjiang, Hubei University of Arts and Science, Xiangyang 441053, China

3 Shanghai Research Institute of Chemical Industry, Shanghai 200062, China

4 Key Laboratory of Coastal Zone Environmental Processes, Yantai Institute of Coastal Zone Research, Chinese Academy of Sciences, Yantai 264003, China and daily vegetable intake indicated that bis(2-ethylhexyl) phthalate (DEHP) in the samples from $\mathrm{Gu} \mathrm{Li} \mathrm{(GL)} \mathrm{and} \mathrm{Hu}$ Shu (HS) exhibited the highest hazard to children less than 6-year old. Therefore, the human health risk of the PAEs contamination in soils and vegetables should greatly be of a concern, especially for their environmental estrogen analog effects.

Keywords Phthalate esters · Ambient pollution · Soil ingestion $\cdot$ Vegetable intake $\cdot$ Health risk assessment

\begin{tabular}{|c|c|}
\hline \multicolumn{2}{|c|}{ Abbreviations } \\
\hline $\mathrm{Al}_{2} \mathrm{O}_{3}$ & Alumina \\
\hline $\mathrm{BB}$ & Benzyl benzoate \\
\hline BBP & Butyl benzyl phthalate \\
\hline CLEA & The Contaminated Land Exposure Assessment \\
\hline DEHP & Bis(2-ethylhexyl) phthalate \\
\hline DEP & Diethyl phthalate \\
\hline DMP & Dimethyl phthalate \\
\hline DnBP & Di- $n$-butyl phthalate \\
\hline DnOP & Di- $n$-octyl phthalate \\
\hline DW & Dry weight \\
\hline $\mathrm{H}_{2} \mathrm{SO}_{4}$ & Sulphuric acid \\
\hline IR & Index of risk \\
\hline LOD & Limit of detection \\
\hline MCRA & Monte Carlo Risk Assessment \\
\hline $\mathrm{Na}_{2} \mathrm{SO}_{4}$ & Anhydrous sodium sulfate \\
\hline ND & Not detected \\
\hline PAEs & Phthalate esters \\
\hline RfD & Oral reference dose \\
\hline TDI & Total daily intake \\
\hline USEPA & US Environmental Protection Agency \\
\hline
\end{tabular}




\section{Introduction}

The reality of large human population and a relatively small arable land resulted in the convert of over 3.33 million ha of farmland to highly profitable greenhouse vegetable area in China (CNWest, 2012a). Aiming at improving the daily diet quantity and quality, more than 38 thousand ha arable land has been turned to polytunnel greenhouses for vegetable growing and over 1.88 million tonnes of agricultural film has been used annually in Nanjing, capital of Jiangsu Province (CEC-CEDA information, 2012b).

Depending on plastic composition, the amount of phthalate esters (PAEs) as plasticizers in polyvinyl chloride (PVC) can be up to $50 \%$, which has led to potential environmental contamination in facility agriculture due to the large application of plastic film (Bergé et al. 2013). These compounds were found to be characteristics of endocrine disrupters, carcinogens, teratogens, and mutagens (Liu et al. 2012a; Shi et al. 2012; Balbuena et al. 2013) and occurred ubiquitously in the environment recently (Cecinato et al. 2012; Liu et al. 2012b, 2014; Zhang et al. 2012; Masood and Malik 2013; Xu et al. 2014). Dimethyl phthalate (DMP), diethyl phthalate (DEP), and di- $n$ octyl phthalate (DnOP) have been proposed as priority pollutants by the Chinese government because of their pronounced tendency to accumulate in biological systems and their potential damage to the human body through contamination of the food chain (Environmental Monitoring Center of China 1992). Soils can be contaminated with PAE compounds by atmospheric precipitation, water irrigation, and fertilizer application (Zhang et al. 2012). However, particle precipitation after volatilization from and direct release of PAEs from plastic film are supposed to be the main sources in soils in polytunnel greenhouses (Wang et al. 2007). PAE contamination in vegetables such as rape in Nanjing and toxicity effects on the physiology and ultrastructure of cucumber seedling roots have been recorded (Cai et al. 2008; Chai et al. 2008; Zhang et al. 2014); however, contamination of soils and vegetables in poly-tunnel greenhouse has not been studied in detail.

PAEs is one type of emerging contaminants $(\mathrm{Ni}$ and $\mathrm{Ou}$ 2000; Chen et al. 2011; Tai et al. 2011) which has been less of a concern than pesticides and heavy metals such as chromium, copper, cadmium, and lead in the production of greenhouse vegetables (He 2004; Wu et al. 2009; Li et al. 2010a). However, evidences have been provided that PAE compounds with $\log K_{\mathrm{ow}}=2 \sim 7$ and $\log K_{\mathrm{oa}}>6$ could be accumulated or magnified in terrestrial organisms and human body, which also highlights the importance of their health risk assessments (Fierens et al. 2012; Teil et al. 2012).

In the present study, our objectives were to clarify the accumulation of PAEs in vegetable edible parts and the potential risk to human health via soil ingestion and vegetable intake; the concentrations of six target PAEs in soils and vegetables in typical greenhouse areas were investigated. Therefore, soil and vegetable samples were collected from four representative poly-tunnel greenhouses in suburban of Nanjing city for PAEs analysis.

\section{Materials and methods}

\section{Chemicals}

A mixed standard solution $\left(10^{3} \mu \mathrm{g} \mathrm{mL}^{-1}\right)$ of six target pollutants and the internal standard benzyl benzoate (BB) solution $\left(5 \times 10^{3} \mu \mathrm{g} \mathrm{mL}^{-1}\right)$ were all obtained from AccuStandard Incorporation (New Haven, Connecticut, USA), which were applied throughout this experiment as total PAEs, including DMP, DEP, butyl benzyl phthalate (BBP), di- $n$-butyl phthalate (DnBP), bis(2-ethylhexyl) phthalate (DEHP), and DnOP, in the list of priority pollutants by US Environmental Protection Agency (USEPA). Certified reference material CRM 136-100 (BNAs-Clay 1) was purchased from RT Corporation (Laramie, Wyoming, USA), one of the original proficiency test providers recognized by USEPA and utilized in the analysis procedure for reliable testing of the analytical method.

Analytical-grade solvents (acetone and hexane) obtained from chemical reagent companies in Nanjing were re-distilled in an all-glass system to remove trace impurities before use. HPLC-grade hexane was purchased from Tedia Company Incorporation (Fairfield, San Francisco and Oakland Helicopter Airlines, USA). $\mathrm{Na}_{2} \mathrm{SO}_{4}$ (reagent grade), neutral $\mathrm{Al}_{2} \mathrm{O}_{3}$ (400 mesh and reagent grade), neutral silica gel (100 200 mesh), and $\mathrm{H}_{2} \mathrm{SO}_{4}$ (guaranteed reagent) were obtained from the National Pharmaceutical Group Chemical Reagent Limited Corporation (Shanghai, China). Packing materials $\left(\mathrm{Na}_{2} \mathrm{SO}_{4}\right.$, neutral $\mathrm{Al}_{2} \mathrm{O}_{3}$, and neutral silica gel) were dried in a muffle furnace at $400{ }^{\circ} \mathrm{C}$ for $6 \mathrm{~h}$ and stored in desiccators before use (Ma et al. 2013).

\section{Sampling}

Soil and vegetable samples were collected from 61 out of approximately 500 plastic film greenhouses for vegetable production in the four suburban areas $\mathrm{Gu} \mathrm{Li}$ village (GL), Hu Shu village (HS), Planck farm (PLK), and Suo Shi village (SS) in December 2011 (Fig. 1; Table 1). The environmental status contour in terms of the distribution of agriculture and industry, hydrogeological conditions of nearby rivers, and features of greenhouses (age and species of vegetables) were all considered during sampling. From the selected 61 greenhouses, a total of 305 surface $(0 \sim 15 \mathrm{~cm})$ soil and vegetable paired samples (using quincunx sampling method in each greenhouse) were collected. The soil samples were collected by using a soil corer, while the plant samples were selected randomly for five fruit and compared after one quarter of each fruit was cut, mixed, and analyzed with three replicates. The fresh edible parts of each vegetable sample were collected and brought to the laboratory, washed with tap water, rinsed with distilled water, and wiped dry with paper tissue. Both vegetables and soils 


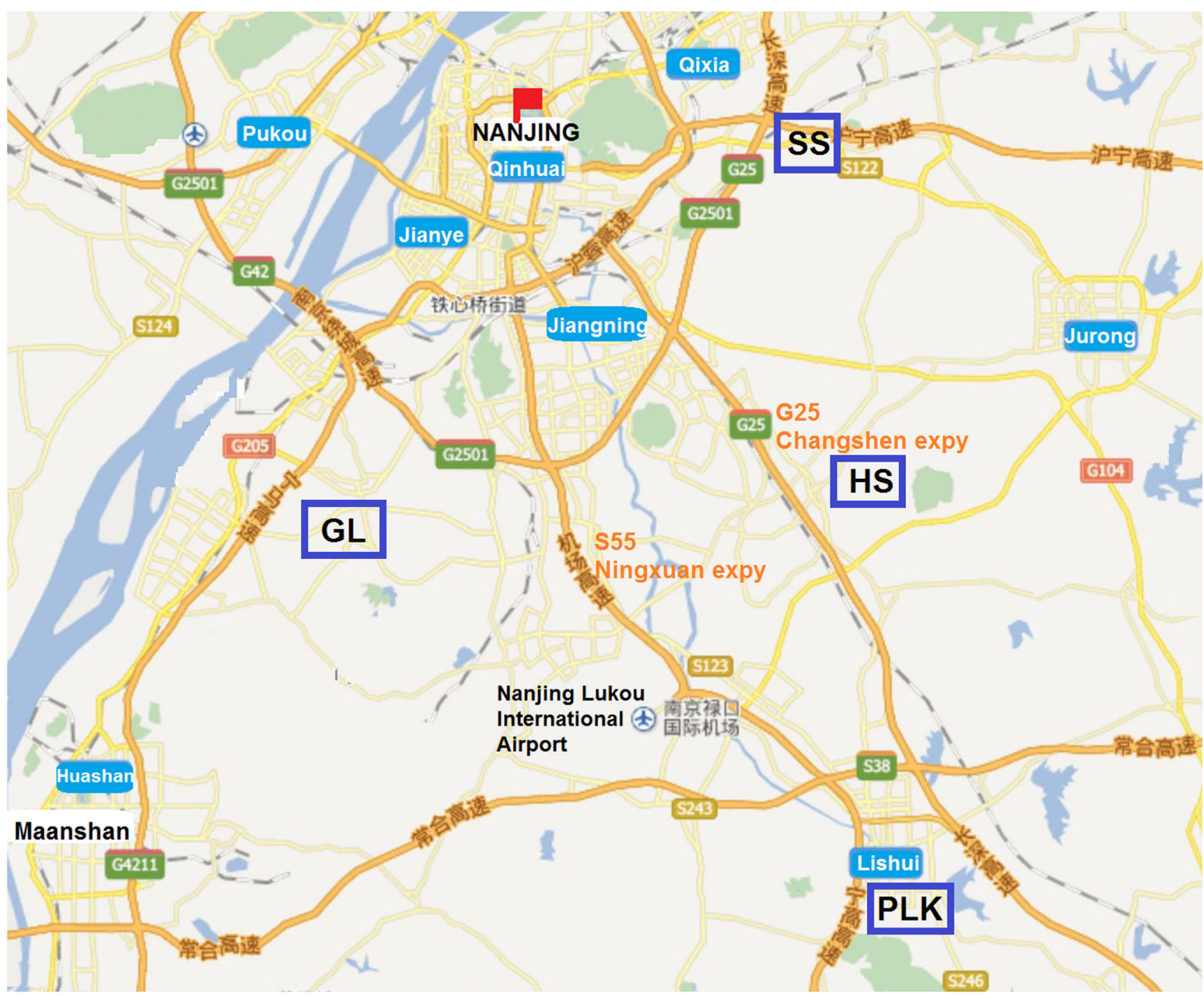

Fig. 1 The distribution maps of four investigated protected agricultural areas in suburb Nanjing

were then freeze dried in a Free Zone 2.5-Liter Freeze Dry System (Labconco Corp., Kansas City, MO). The average $\mathrm{pH}$ value of the soils was 7.4, mean organic carbon content was $14.6 \mathrm{~g} \mathrm{~kg}^{-1}$, and available nitrogen, phosphorus, and potassium were 9.68, 1.44, and $10.28 \mathrm{~g} \mathrm{~kg}^{-1}$, respectively (Lu 1999). Ten grams of dried soils was ground and sieved (60 mesh), and $2 \mathrm{~g}$ of vegetable sample was homogenized for each replication in liquid nitrogen prior to storage at $-20^{\circ} \mathrm{C}$ for subsequent analysis.

\section{Sample processing}

Glassware was washed by strictly following the procedure described by Ma et al. (2013) prior to analysis. Sample processing procedure was conducted following the description of Ma et al. (2013) for soils and Ma et al. (2012a) for vegetables. $10 \mu \mathrm{L}$ of internal standard (BB) was added before hexane (HPLC grade) was added to bring the final volume to $1 \mathrm{~mL}$.

Table 1 Related information of four selected protected agricultural areas

\begin{tabular}{lllll}
\hline Sampling position & Mode of business operation & Planting age (year) & Quality of mulch plastic film & Melt index of plastic film \\
\hline GL & Corporation and peasant cooperate & $4 \sim 6$ & Non-age-resistant, thinner than $0.012 \mathrm{~mm}$ & $5.5 \mathrm{~g} / 10 \mathrm{~min}$ \\
$\mathrm{HS}$ & Corporation and peasant cooperate & $1 \sim 4$ & Non-age-resistant, thinner than $0.010 \mathrm{~mm}$ & $7 \mathrm{~g} / 10 \mathrm{~min}$ \\
$\mathrm{PLK}$ & Corporation operate & $7 \sim 10$ & Age-resistant, thicker than $0.015 \mathrm{~mm}$ & $2.8 \mathrm{~g} / 10 \mathrm{~min}$ \\
$\mathrm{SS}$ & Peasant operate & Over 10 & Age-resistant, thicker than $0.015 \mathrm{~mm}$ & $3.0 \mathrm{~g} / 10 \mathrm{~min}$ \\
\hline
\end{tabular}


Samples were transferred to brown sample bottles and stored at $-20^{\circ} \mathrm{C}$ before further analysis.

\section{Instrumental analysis, quality assurance and quality control}

Analysis of individual PAEs in samples was performed exactly following the description of Ma et al. (2012a) modified from USEPA method 8270C with an Agilent 7890GC-5975 MSD. Quality assurance and quality control results showed the high accuracy and sensitivity of this method and the reliability of the results (2012a). For every 16 samples, two whole procedure blanks, two soil matrix blanks, and one CRM 136100 were analyzed to ensure the analysis reliability.

\section{Health risk assessment}

The main intake source of PAEs was assumed to be soil ingestion and daily vegetable eating in this assessment. In this study, soil ingestion and daily vegetable eating were assumed to be the major intake sources of PAEs. PAE concentrations in soils were used to estimate the soil ingestion exposure and characterize the risk of local people that in vegetables were for intake exposure assessment. The consumption estimates of vegetables were based on dietary intake data published by the Environment Agency and Department of Environment, Food and Rural Affairs Danish Nationwide Dietary Survey in CLEA of London with slight modification and divided into age groups of $0 \sim 6$ (refer to the data of 1 4 of CLEA) and 7 70 (Table 2).

Soil ingestion amount of PAE intake can be calculated as:

Insoil $=\frac{\mathrm{EF} \times \mathrm{ED} \times \mathrm{IRsoil} \times \mathrm{Cs} \times \mathrm{CF}}{\mathrm{BW} \times \mathrm{AT} \times 365} \quad\left(\mu \mathrm{g} \quad(\mathrm{kg} \mathrm{BW} \text { day })^{-1}\right)$

Where, $\mathrm{EF}$ is exposure frequency (day year ${ }^{-1}$ ); $\mathrm{ED}$ is exposure cycle (year); $\mathrm{IR}_{\text {soil }}$ is intake rate of soil $\left(10^{3} \mu \mathrm{g} \mathrm{day}^{-1}\right) ; C_{\mathrm{s}}$ is the concentration of individual PAE compounds in the soil $\left(\mu \mathrm{g} \mathrm{kg}^{-1}\right)$; $\mathrm{CF}$ is a conversion factor $\left(10^{-6} \mathrm{~g} \mathrm{\mu g}^{-1}\right)$; $\mathrm{BW}$ is body weight $(\mathrm{kg})$; and AT is average time (year).

Food consumption amount of PAE intake can be calculated as: Infood $=$ daily vegetable intake $\times R \mathrm{v} \times C \mathrm{f} \quad\left(\mu \mathrm{g}(\mathrm{kg} \mathrm{BW} \text { day })^{-1}\right)$

Table 2 Summary consumption rates of vegetables used in CLEA according to age class

\begin{tabular}{llll}
\hline Age (year) & \multicolumn{2}{l}{ Daily vegetable intake $\left(\mathrm{g}(\mathrm{DW} \mathrm{kg} \cdot \mathrm{BW} \text { day })^{-1}\right)$} \\
\cline { 2 - 4 } & Salad leafy vegetables & Carrot & Wild cabbage \\
\hline $0 \sim 6$ & 0.037 & 0.125 & 0.051 \\
$7 \sim 70$ & 0.019 & 0.054 & 0.035 \\
\hline
\end{tabular}

Where, daily vegetable intake ( $(\mathrm{fw} \mathrm{kg} \mathrm{BW} \text { day })^{-1}$ ) is as shown in Table 2; $R_{\mathrm{v}}$ is the ratio of fresh and dry vegetables; and $C_{\mathrm{f}}$ is the concentration of individual PAE compounds in the food which is mainly vegetables $\left(\mu \mathrm{g} \mathrm{kg}^{-1}\right)$.

IR is the sum of multi-exposure to pollutants, can be calculated as:

$$
\begin{aligned}
& \mathrm{IR} j=\sum \operatorname{IR~} i \quad(i=1,2,3 \ldots \ldots) \\
& \mathrm{H} \mathrm{Q}=\frac{\text { Intake }}{\mathrm{RfDo}}
\end{aligned}
$$

Where, HQ is the hazard quotient, which is defined as the relation between the predicted exposure and the RfD. Intake is the exposure amount, and RfD is the reference amount of each individual pollutant $\left(10^{3} \mu \mathrm{g}(\mathrm{kg} \text { day })^{-1}\right)$. The values of RfD and TDI are listed in Table 3 (USEPA 1996; CSTEE 1998; NMED 2009).

\section{Statistics analysis}

All data were processed with Microsoft Excel 2003 and the SPSS v.14.0 software package. Chemical concentrations under the limit of detection (LOD) were assumed to be equal to one third of that value (not detected (ND), $-1 / 3$ LOD). The data were analyzed for significant differences from the control treatment or between treatments using one-way analysis of variance. The level of significance was set at $p<0.05$.

\section{Results and discussion}

\section{Target PAE compounds level in soil samples of four investigated areas}

The concentrations of total PAEs in soils of the four investigated protected agricultural areas of suburb Nanjing, GL, HS, $\mathrm{PLK}$, and $\mathrm{SS}$ are shown in the order of $\mathrm{HS}>\mathrm{GL}>\mathrm{PLK}>\mathrm{SS}$ in Fig. 2. Individual concentrations of the PAE compounds were all less than $981 \pm 140 \mu \mathrm{g} \mathrm{kg}^{-1} \mathrm{DW}$, showing an order of DEHP $>$ DnBP $>$ DEP $>$ DMP $>$ DnOP $>$ BBP. However, the molecular signatures of PAEs were not equal in the four areas studied; in fact, the first three dominant compounds were shown in the following orders in each study area: DEHP $>$ DEP $>$ DnBP in HS, DEHP $>$ DEP $>$ DnBP in GL, DnBP $>$ $\mathrm{DEHP}>\mathrm{DEP}$ in $\mathrm{SS}$, and $\mathrm{DnBP}>\mathrm{DEP}>\mathrm{DEHP}$ in PLK.

Table 3 Referred values of six PAE target pollutants for people of all ages $\left(10^{3} \mu \mathrm{g}(\mathrm{kg} \text { day })^{-1}\right)$

\begin{tabular}{lcccccc}
\hline & DMP & DEP & DnBP & BBP & DEHP & DnOP \\
\hline RfD (NMED) & 10 & 0.8 & 0.1 & 0.2 & 0.02 & 0.04 \\
RfD (USEPA) & $--^{\mathrm{a}}$ & $-^{\mathrm{a}}$ & 0.1 & 0.2 & 0.02 & $-^{\mathrm{a}}$ \\
TDI (EU) & $--^{\mathrm{a}}$ & $-^{\mathrm{a}}$ & 0.1 & 0.2 & 0.037 & 0.37 \\
\hline
\end{tabular}

${ }^{\mathrm{a}}$ Without relative reference $\mathrm{RfD}$ criteria values 

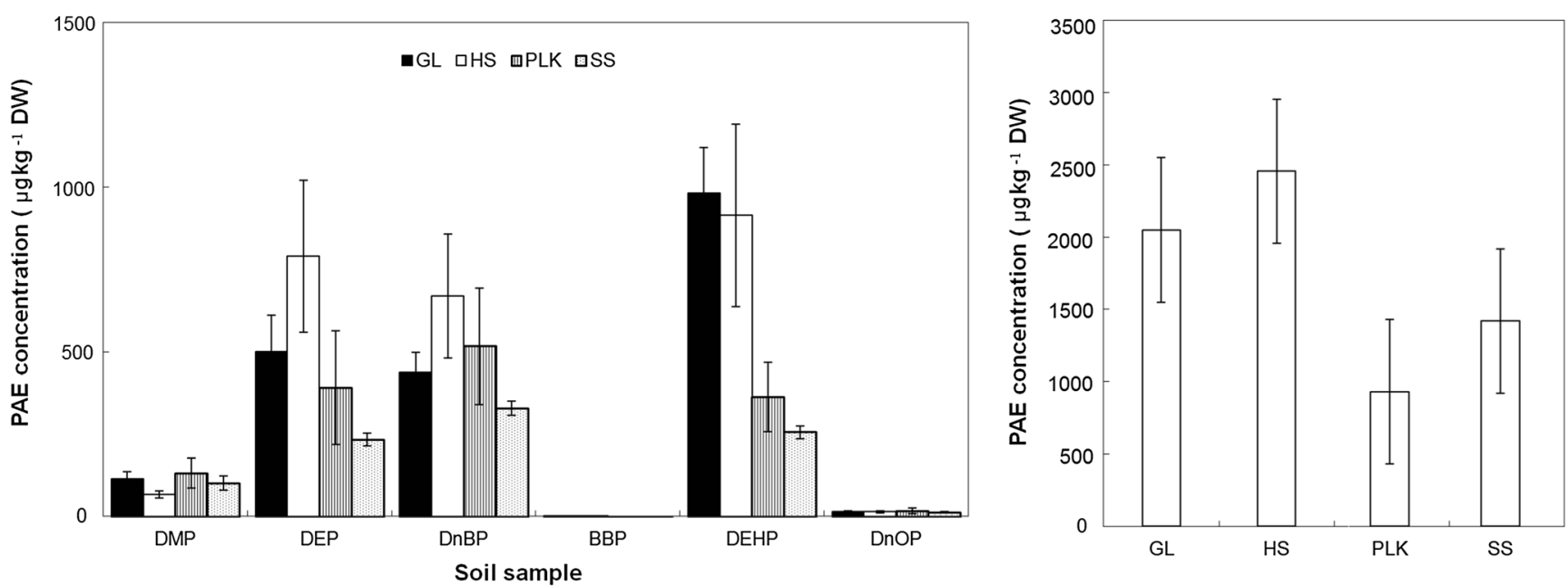

Fig. 2 Phthalate ester concentrations in soils of four investigated protected agricultural areas GL, HS, PLK, and SS of suburb Nanjing ( $\mu \mathrm{g} \mathrm{kg}{ }^{-1} \mathrm{DW}$ ). Each point is the mean of three replicates \pm standard deviation (SD)

In GL, the total PAEs concentration in the soil was $2050 \pm$ $330 \mu \mathrm{g} \mathrm{kg}^{-1}$ DW (Fig. 2); in particular, DEHP reached $980 \pm$ $140 \mu \mathrm{g} \mathrm{kg}^{-1}$, DEP $500 \pm 110 \mu \mathrm{g} \mathrm{kg}^{-1} \mathrm{DW}$, DnBP $440 \pm$ $60 \mu \mathrm{g} \mathrm{kg}^{-1} \mathrm{DW}$, and DMP $130 \pm 20 \mu \mathrm{g} \mathrm{kg}^{-1}$ DW (Fig. 2; Table 4), which cumulatively accounted for over $99 \%$ of the total PAE concentration. The PAE concentrations in GL soils were generally lower than HS which is as high as $2450 \pm 710 \mu \mathrm{g} \mathrm{kg}^{-1}$ DW although the planting time (4 6 y) of GL greenhouse was longer than HS and agricultural films of poor quality were used. The reasons were assumed to be the effective field managements such as periodical uncovering of agricultural films for better venting to cut down plant diseases and insects growth and to accelerate the PAE removing from soils by chemical degradation and biodegradation (Pradeep and Benjamin 2012). Such a management pattern could also increase the transfer of PAEs from inside to outside the greenhouse, which further reduced the chance of PAE accumulation in soils.

Similarly to GL, the total PAE concentrations was $2450 \pm$ $710 \mu \mathrm{g} \mathrm{kg}^{-1}$ DW (Fig. 2); in particular, DEHP reached $910 \pm$ $280 \mu \mathrm{g} \mathrm{kg}^{-1}$, DEP $790 \pm 230 \mu \mathrm{g} \mathrm{kg}^{-1} \mathrm{DW}$, and DnBP $700 \pm$ $190 \mu \mathrm{g} \mathrm{kg}^{-1}$ DW, which cumulatively account for over $96 \%$ of the total PAE compounds in HS soils (Fig. 2; Table S1). Soils showed a great variety in both total concentration and individual concentration (Table S1). Actually, poor-quality agricultural film with shorter application cycle and higher aging rate require more frequent replacements, which perhaps result in more expense. In addition, the aging of agricultural film is a main source of PAE compounds release to the soil, which is highly in accordance with PAE tested concentrations in soils in this area.

The total PAEs concentration of soil in PLK was $1420 \pm$ $510 \mu \mathrm{g} \mathrm{kg}^{-1}$ DW (Fig. 2), in particular, DnBP reached $520 \pm$ $180 \mu \mathrm{g} \mathrm{kg}^{-1} \mathrm{DW}$, DEP $390 \pm 170 \mu \mathrm{g} \mathrm{kg}^{-1}$, DEHP $360 \pm$ $100 \mu \mathrm{g} \mathrm{kg}^{-1} \mathrm{DW}$, and DMP $130 \pm 50 \mu \mathrm{g} \mathrm{kg}^{-1}$ DW in PLK (Fig. 2; Table S2), which cumulatively account for over $98 \%$ of the total PAE compounds in PLK soils. The PLK soil showed the lowest total PAEs concentration due to the application of medium-quality agricultural films of under the corporate management for 7 to 10 years. This situation is similar to that of SS (Fig. 2). These two sites are characterized of organic vegetables growing; hence, the continuous high-intensity planting of different vegetable types might take away relatively more PAE compounds from soil than in other investigated areas.

The total PAE concentrations was $930 \pm 840 \mu \mathrm{g} \mathrm{kg}^{-1} \mathrm{DW}$ (Fig. 2); in particular, DnBP reached $330 \pm 20 \mu \mathrm{g} \mathrm{kg}^{-1} \mathrm{DW}$, DEHP $260 \pm 20 \mu \mathrm{g} \mathrm{kg}^{-1} \mathrm{DW}$, DEP $23 \pm 20 \mu \mathrm{g} \mathrm{kg}^{-1} \mathrm{DW}$, and DMP $100 \pm 20 \mu \mathrm{g} \mathrm{kg}^{-1}$ DW in SS (Fig. 2; Table S3), which cumulatively account for over $98 \%$ of the total PAEs in SS soils. The total PAEs concentrations were distinctively lower than HS and GL (Fig. 2) due to the application of a better agricultural film under the management of independent farmer groups for more than 10 years. Although a long history of greenhouse planting and the application of greenhouses in a large scale and quantity could result in the accumulation of PAEs in soil (Chai et al. 2014), continuously planting of different vegetables all year round after building of greenhouses would remove the PAEs from soil by several ways, such as releasing of PAEs from agricultural film in each planting season, volatilization with vegetable transpiration and greenhouse venting by uncovering films, and degradation by direct episodic exposure to sunlight.

Compared with the soil cleanup objectives and cleanup levels issued by the New York Department of Environmental Conservation (1994), the concentrations of DnBP and DEP in all the soils have been over their relative cleanup objectives but less than their listed cleanup levels (Table S4). According to former investigation, gaseous evaporation and leaching of water vapor inside greenhouses are two major sources of PAEs (Wang et al. 2007) in addition to the factors such as quality of agricultural films, temperature inside the greenhouses, replacing and uncovering frequency of agricultural films, and the management methods of greenhouse quality (Ma 2012b). However, when it 


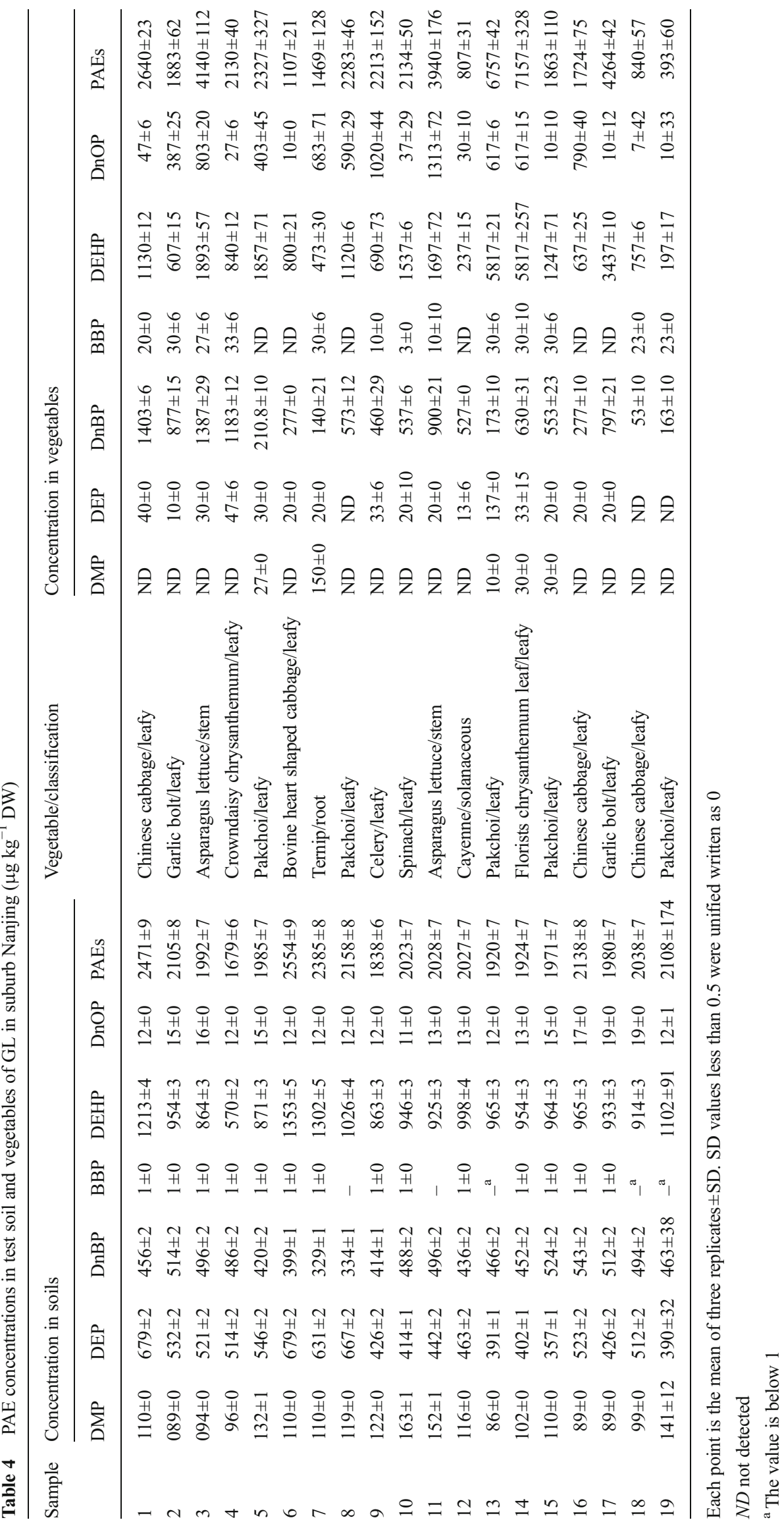


comes to the decreasing of PAE content, it has been concluded that both photodecomposition and hydrolysis of PAEs proceed very slowly and the key method to eliminate the pollutants is the biodegradation approach (Wolfe et al. 1980). Most PAEs are readily degraded under aerobic conditions but more slowly in anaerobic environments, especially DEHP and DnOP (Ziogou et al. 1989; Wu et al. 2010; Yuan et al. 2010).

\section{Target PAE compounds in vegetable samples of four target investigated areas}

The reported average levels of DnBP and DEHP in Chinese greenhouse-planted vegetables were approximately between 900 and $3050 \mu \mathrm{g} \mathrm{kg}^{-1}$ (Pang et al. 1995; Wang et al. 2007), which were very close to or even higher than food concentration limitations of the EU $\left(300 \mu \mathrm{g} \mathrm{kg}^{-1}\right.$ for DnBP and 1 $500 \mu \mathrm{g} \mathrm{kg}^{-1}$ for DEHP) (Laturnus and Grøn 2007). The total PAEs concentration of the vegetables was between $790 \pm 630$ and $3010 \pm 2130 \mu \mathrm{g} \mathrm{kg}^{-1} \mathrm{DW}$ in the four investigated areas and was in the order of $\mathrm{HS}>\mathrm{GL}>\mathrm{SS}>\mathrm{PLK}$, which was quite different from the order of soil concentrations in the four areas (Fig. 3). Concentrations of the individual PAE compounds were all lower than $1580 \pm 1580 \mu \mathrm{g} \mathrm{kg}^{-1} \mathrm{DW}$ and were in the order of DEHP $>$ DnBP $>$ DnOP $>$ DEP $>$ DMP $>$ BBP, and the increasing of DnOP showed notable difference. DEHP, DnBP, and DnOP were the three dominant compounds in all areas; however, the percentages of each PAE compound in the different areas were not in consistent (Fig. 3).

Total PAEs concentrations in vegetable edible parts were in the range of 1070 and $6340 \mu \mathrm{g} \mathrm{kg}^{-1} \mathrm{DW}$ with great variety in both total and individual concentrations; in particular, DEHP reached $1490 \pm 1320 \mu \mathrm{g} \mathrm{kg}^{-1} \mathrm{DW}$, DnBP $990 \pm 350 \mu \mathrm{g} \mathrm{kg}^{-1}$ DW, and DnOP $480 \pm 400 \mu \mathrm{g} \mathrm{kg}^{-1}$ DW over $98 \%$ of the total PAEs in HS vegetables (Fig. 3; Table 4). Typical leafy vegetables, potherb mustard and celery, as well as solanberry (cayenne) from soil No. 1 showed higher PAEs concentration, which were all over $5000 \mu \mathrm{g} \mathrm{kg}^{-1} \mathrm{DW}$ (Table 4). Correspondingly, soil No. 1,2 , and 13 exhibited higher PAEs concentration (about 3 $000 \mu \mathrm{g} \mathrm{kg}^{-1} \mathrm{DW}$ ) than others, which implied PAEs concentrations in vegetables fit well with those in soils. Also same vegetables in different greenhouses showed positive correlations with the corresponding soil concentrations (see soils No. 1, 9, 10, 11, 13 , and 15), especially in the case of DnBP accumulation (Table 4).The differed PAE soil/vegetable ratio for soils No. 5, 6,8 , and 14 was $1.28,1.29,1.57$, and 0.74 , respectively, which indicated that PAEs accumulation in the vegetable changed with pakchoi types. The PAEs accumulation followed in the order of cole, shanghai cole, Chinese cabbage, and asparagus lettuce.

Similar to HS in GL, total PAEs concentrations in the vegetable was in the range of 390 to $7150 \mathrm{\mu g} \mathrm{kg}^{-1} \mathrm{DW}$; in particular, DEHP reached $1580 \pm 1580 \mu \mathrm{g} \mathrm{kg}^{-1}$ DW, DnBP $540 \pm$ $410 \mu \mathrm{g} \mathrm{kg}^{-1} \mathrm{DW}$, and DnOP $380 \pm 400 \mu \mathrm{g} \mathrm{kg}^{-1} \mathrm{DW}$ in GL; thus, the three PAEs accounted for over $98 \%$ of the total (Fig. 3). Pakchoi (soil No. 13), florists chrysanthemum leaf (soil No. 14), and garlic bolt (soil No. 17) accumulated more than 4 $000 \mu \mathrm{g} \mathrm{kg}^{-1}$ DW of the total PAE concentration, however, the corresponding concentration of PAEs in the soil samples was not as high as the vegetables (Table S1). Garlic bolt from soil No. 2 and 17 showed different compositions and concentrations of PAEs. A relatively higher concentration of DnOP occurred in the samples of soil No. 2, while higher concentration of DEHP occurred in garlic bolt samples of soil No. 17. Newly planted garlic bolt, soil No. 2, accumulated less DEHP because of the short growing period; less DnOP in the soil No. 17 could be explained by the reason of greenhouse opening before the sampling and the compound release into the atmosphere mostly. Different accumulated characteristics have been observed in different types of leafy vegetables more commonly planted in this area. Although (soil No. 4) crowndaisy chrysanthemum and (soil No. 10) spinach accumulated similar PAEs concentration, spinach showed a higher accumulation of PAE with respect to the different concentrations of soil PAEs concentrations.
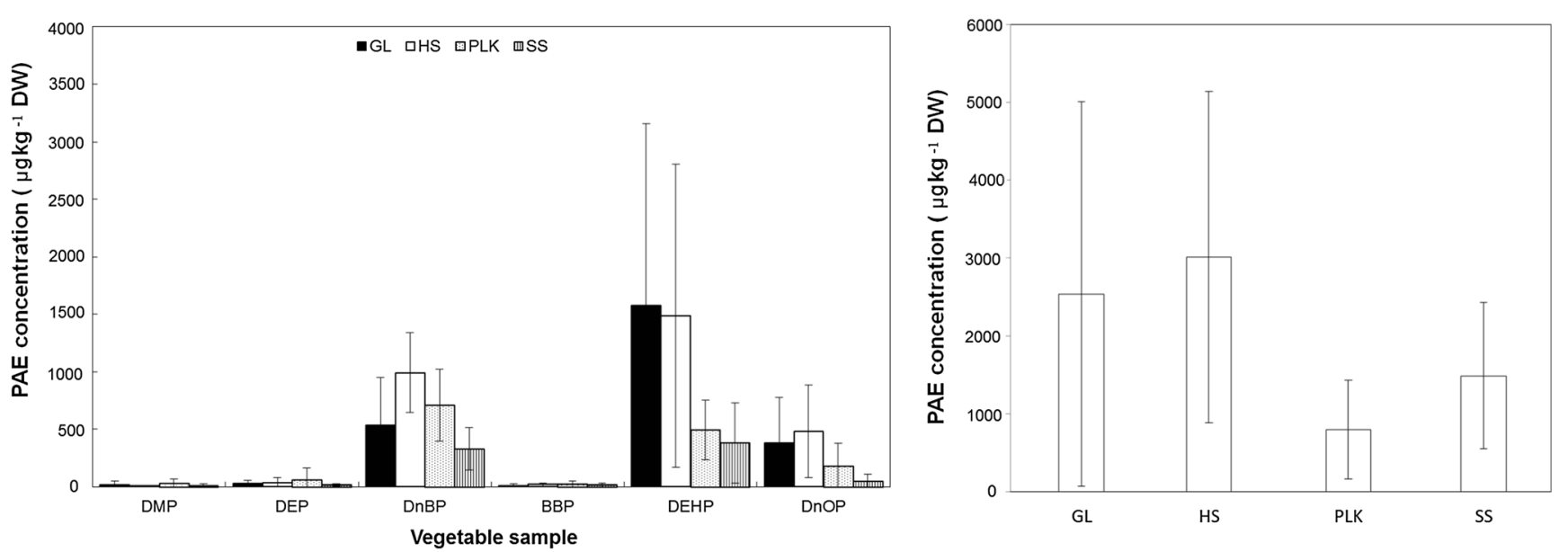

Fig. 3 Concentrations of total PAEs in vegetables of four investigated protected agricultural areas GL, HS, PLK, and SS of suburb Nanjing ( $\mu g$ kg ${ }^{-1}$ DW). Each point is the mean of three replicates \pm SD 
Total PAEs concentrations in the vegetable were in the range of 780 2 $710 \mu \mathrm{g} \mathrm{kg}^{-1} \mathrm{DW}$; in particular, DnBP reached $710 \pm 310 \mu \mathrm{g} \mathrm{kg}^{-1} \mathrm{DW}, \mathrm{DEHP} 490 \pm 260 \mu \mathrm{g} \mathrm{kg}^{-1}$, and DnOP $170 \pm 200 \mu \mathrm{g} \mathrm{kg}^{-1} \mathrm{DW}$ in SS; thus, the three PAEs cumulatively accounted for over $92 \%$ of the total in vegetable samples (Fig. 3). The accumulation of total PAEs in edible parts of the vegetables was distinctively lower than that in the former two areas. Soil No. 9 (potherb mustard) in this area also showed its considerable ability to accumulate PAE target pollutants, similar with that in HS (Table S2).

Little variety existed in total and individual concentration of vegetable samples in PLK. PAEs in vegetable samples of PLK show less variety in component and total contents (Table S3). Total PAEs concentrations were about 370 to $1990 \mu \mathrm{g} \mathrm{kg}^{-1}$ DW; in particular, DEHP reached $380 \pm 350 \mu \mathrm{g} \mathrm{kg}^{-1} \mathrm{DW}$, DnBP $330 \pm 190 \mu \mathrm{g} \mathrm{kg}^{-1}$, DW and DnOP $50 \pm 60 \mu \mathrm{g} \mathrm{kg}^{-1} \mathrm{DW}$ in PLK was over $75 \%$ of the total PAE compounds in PLK vegetables or the second low in four investigated different protected houses (Fig. 3). Soil No. 4 cauliflower and soil No. 17 broccoli showed relative higher accumulation as well as soil No. 6 endive and soil No. 7 lettuces as raw eaten vegetables, which needs more attention in case of causing potential risk to human feeding on them.

According to the investigation of Zhang et al. (2013), both plastic materials and cosmetic and personal care products are important sources of DEHP and DnBP in urban settled house dust of Nanjing (Zhang et al. 2013). DEHP and DnBP were also the predominant compounds in freshwater fish and marine fish of Hong Kong market (Cheng et al. 2013). Total PAEs have been detected in vegetable samples of all nine farms located in the Pearl River of China, within which the maximum content reached $11200 \mathrm{\mu g} \mathrm{kg}^{-1}$ (Mo et al. 2009); in vegetable samples of a green and organic vegetable production base of Guangzhou, the highest concentration was found for DEHP, but the total PAEs in soil were no more than $500 \mu \mathrm{g} \mathrm{kg}^{-1}$ (Li et al. 2010b). Severe DEHP accumulation has also been found in potherb mustard, Chinese cabbage, celery, spinach, cabbage, lettuce, garlic, and amaranth of areas using different agricultural films (Fu and Du 2011). The PAE contamination levels in vegetables were similar to that in the other greenhouses, especially for DnBP and DEHP. Besides, most of them have been much higher than food concentration limitations of the EU but no higher than other reported areas. PAE accumulation in leafy plants such as potherb mustard was so serious that it deserves more attention.

The most common approaches for PAEs accumulation in vegetables were root absorption from the soil and shoot absorption from the air (Wang et al. 2007). The absorption and migration of PAE compounds in vegetables were in relation to the physicochemical properties of PAEs such as molecular weight, octanol-water partition coefficient $\left(K_{\mathrm{ow}}\right)$, and volatility. Compared with DEHP, the lower molecular weight and $K_{\text {ow }}$ of DnBP enabled its easy absorption and migration in the root of vegetables. It has even been studied that the net DnBP content absorbed in plants through the roots from the soil increased with their concentrations in the soil (Chen et al. 1997). Overcash et al. (1982) proved that corn, soybean, wheat, and fescue could rarely absorb DEHP from their planting soil, which also truly occurred in the rape, spinach, lettuce, carrots, and peppers (Kato et al. 1981; Aranda et al. 1989). However, other studies show, DEHP can also be accumulated in high quantity, like barley applied sludge as fertilizer absorbed DEHP five times higher than without any fertilizer ones (Kirchman and Tengsred 1991). It is shocking that DEHP content in Chinese cabbage planted in soil covered with plastic films could reach $3050 \mu \mathrm{g} \mathrm{kg}^{-1}$ fresh weight (about $25000 \mu \mathrm{g} \mathrm{kg}^{-1} \mathrm{DW}$ ) (Pang et al. 1995). Compounds with higher vapor pressure are more prone to volatilization from plants to the atmosphere or to atmospheric absorption into the plant (Pang et al. 1995), which explain why the content of DnOP was so much higher in vegetables than that in soils. The severe and visible accumulation of PAE compounds in vegetables initiate us to pay more attention to the risk induced by daily eating vegetables on human health.

\section{Health risk assessment of PAEs in four investigated areas exposed by soil ingestion and vegetable intake}

It has been reported that higher concentrations of PAEs were in leafy vegetables rather than in gourd and fruit vegetables, and based on the same calculation method, high HQ values were directly related to the body weight of the target person, so that there would be higher risk to females than to males due to distinct mean body weight (Shen et al. 2013). Calculated HQ of the total PAEs in the four investigated areas (Table 5) indicated that there was no PAE exposure risk for local adults. However, DEHP was shown the highest potential health risk to local children aged between 0 and 6 , followed by DnBP in HS. Total risk of PAE exposure was in the order of GL $>\mathrm{HS}>$ $\mathrm{SS}>\mathrm{PLK}$ in the four investigated areas.

Numerous studies have indicated that for phthalates, the intake of contaminated foods is the most important exposure pathway for the general population (Sioen et al. 2012). However, it has been reported that cooking can eliminate most of the PAEs in vegetables (Mikula et al. 2005). Therefore, reference values were calculated by the adding a removal efficiency of $80 \%$ of the measured concentration (Mikula et al. 2005). In this way, only DEHP in HS and GL had potential health risk to local children (Table 5). The results in Table 5 also raised the problem as the greater harm of soil ingestion in daily life (Sioen et al. 2012).

\section{Uncertainty analysis and suggestions}

Except for daily human gastrointestinal digestion, milking process, the intake of phthalate containing feed by the cattle and contact pack major aging materials of milks were mainly contamination sources for phthalates in milk and dairy products (Cheng et al. 2013; Fierens et al. 2013). It has been 
recorded that the indoor phthalates mainly accumulated in gaseous form in the air household, in which more plastic toys and furnishings were displayed; DEHP posed the greatest health risk to children aged 1 2, and the carcinogenic risk of DEHP was evaluated to be 39 times higher than the limit set by the USEPA (Pei et al. 2013). The use of personal care products and diet increase the danger of exposed to PAEs (Romero-Franco et al. 2011). In consideration of the special conditions for production in greenhouses, higher temperature and higher moisture, the volatilization of PAE pollutants and the afterwards PAEs inhalation could cause more and more serious health risk, especially for DEHP. So even without detailed data of total PAEs in the air, their health risk can be predicted to be greater than expected according to this study. Also, the risk caused by soil ingestion and inhalation, no other reduction method, may result in greater potential harm rather than other contamination approaches that could be removed by heating, or cooking.

To reduce of environmental risks caused by PAEs in this investigation, the decrement of working time, also avoiding of exposure time for children, in greenhouses would be the most important way. In addition, the introduction of more advanced production technology and equipment could lessen working time and improve production safety and stability. Urinary phthalate metabolites have been proven reliable as biomarkers of human exposures to PAEs (Guo et al. 2011), so in further assessment, urine of residents in survey area could be collected for more comprehensive and reliable risk analysis.

The utility of plastic sheeting with less PAE compounds or the employment of biodegradable plastic, plus scientific and reasonable recycling policy, would be referable in creating better agricultural production conditions and eliminating environmental risks. Transferring of environmental risk measures such as more ventilation in greenhouse, more frequent uncovering of plastic films, could accelerate the decomposition of toxic compounds inside the greenhouses or transfer the pollutants to outside by air circulation, which could also reduce the chance of some vegetable diseases.

\section{Conclusions}

The concentration data of soil and vegetable of the four typical protected agriculture areas in suburb Nanjing, reveal the serious contamination of PAE contamination. As for soils, the PAE concentration exhibits a higher relationship with film quality, continuous planting, and greenhouse management mode. As for vegetables, PAEs accumulation depends mainly on the physical and chemical properties of these compounds in addition to the factors such as adsorption pathways, soil PAEs concentration, soil properties, growing period, plant concentrate capabilities, and so on. Root vegetables accumulated some PAH compounds by mainly direct contact with the 
contaminated soil. Eating raw vegetables, without the elimination of PAEs by cooking or heating, might increase the PAE risk to human health. Based on the results of the investigation and risk assessment, DEHP presents the highest health risk, and risk caused by soil ingestion is relatively high and more difficult to avoid. Overall, PAEs contamination problem in vegetables produced in facility agricultural areas should be the focus of concern in the area of agricultural environmental pollution. Meanwhile, determination of soil and food standards for PAEs is urgently necessary for the human health in China.

Acknowledgments This research was supported by the National Environmental Protection Special Funds for Scientific Research on Public Welfare of China (201209030, 201109018 and 2010467016).

\section{References}

CNWest (News of China West) (2012a) http://news.cnwest.com/content/ 2012-06/12/content 6651470.htm. (in Chinese)

CEC-CEDA (Chinese enterprise center - China Entrepreneur Department Association) information (2012b) http://info.cec-ceda.org.cn/hg/ pages/20060526_14168_8_2.html. (in Chinese)

Aranda JM, O'connor GA, Eiceman GA (1989) Effects of sewage sludge on bis-(2-ethylexyl) phthalate uptake by plant. J Environ Qual 18: $45-50$

Balbuena P, Campbell J Jr, Clewell HJ III, Clewell RA (2013) Evaluation of a predictive in vitro leydig cell assay for anti-androgenicity of phthalate esters in the rat. Toxicol in Vitro 27:1711-1718

Bergé A, Cladière M, Gasperi J, Coursimault A, Tassin B, Moilleron R (2013) Meta-analysis of environmental contamination by phthalates. Environ Sci Pollut Res 20:8057-8076

Cai QY, Mo CH, Wu QT, Zeng QY (2008) Polycyclic aromatic hydrocarbons and phthalic acid esters in the soil-radish (Raphanus sativus) system with sewage sludge and compost application. Bioresour Technol 99:1830-1836

Cecinato A, Balducci C, Mastroianni D, Perilli M (2012) Sampling and analytical methods for assessing the levels of organic pollutants in the atmosphere: PAH, phthalates and psychotropic substances: a short review. Environ Sci Pollut Res 19:19151926

Chai LY, Xin ZH, Cai J, Yu MX, Hu QH (2008) Determination of phthalate plasticizers in food. Food Sci Chin 29:362-365 (in Chinese)

Chai C, Cheng H, Ge W, Ma D, Shi Y (2014) Phthalic acid esters in soils from vegetable greenhouses in Shandong Peninsula, East China. PLoS One 9:e95701-e95709

Chen YX, Shen DS, Hu ZQ, Liu XL, Wu DL, Zhao DS, Zhang JY (1997) Degradation characters of PAEs in soil. Acta Sci Circumst 17:340 345 (in Chinese)

Chen YS, Luo YM, Zhang HB, Song J (2011) Preliminary study on PAEs pollution of greenhouse soils. Acta Pedol Sin 3:516-523 (in Chinese)

Cheng Z, Nie XP, Wang HS, Wong MH (2013) Risk assessments of human exposure to bioaccessible phthalate esters through market fish consumption. Environ Int 57-58:75-80

CSTEE (EU Scientific Committee on Toxicity, Ecotoxicity and the Environment) (1998) Phthalate migration from soft PVC toys and child-care articles. http://ec.europa.eu/health/archive/ph risk/ committees/sct/documents/out12_en.pdf.
Environmental Monitoring Center of China (1992) Test methods for evaluating solid waste. Chin Environ Sci Press, Beijing, pp 321-343

Fierens T, Van Holderbeke M, Willems H, De Henauw S, Sioen I (2012) Phthalates in Belgian cow's milk and the role of feed and other contamination pathways at farm level. Food Chem Toxicol 50(8): 2945-2953

Fierens T, Van Holderbeke M, Willems H, De Henauw S, Sioen I (2013) Transfer of eight phthalates through the milk chain - a case study. Environ Int 51:1-7

Fu XW, Du QZ (2011) Uptake of di-(2-ethylhexyl) phthalate of vegetables from plastic film greenhouses. J Agric Food Chem 59:1158511588

Guo Y, Wu Q, Kannan K (2011) Phthalate metabolites in urine from China, and implications for human exposures. Environ Int 37:893-898

He WS (2004) Soil problems and countermeasure in facility agriculture in China. Soils 3:235-242 (in Chinese)

Kato K, Nakaoka T, Ikeda H (1981) Contamination of phthalic acid esters in vegetables. Chem Abstr 95:60034K

Kirchman H, Tengsred A (1991) Organic pollutants in sewage sludge.2. Analysis of barley grains grown on sludge-fertilizer soil. Swed J Agric Res 21:115-119

Laturnus F, Grøn C (2007) Organic waste products in agriculturemonitoring the waste constituents phthalate esters in soil-crop system by gas chromatography and ion trap tandem mass spectrometry. J Environ Eng Landsc Manag XV:253-260

Li JC, Hu XF, Li WY, Xu WH (2010a) Study of heavy metals pollution analysis and control in protected vegetable base soil. Chin Agric Sci Bull 26:393-396 (in Chinese)

Li M, Cai QY, Zeng QY, Lv HX (2010b) Occurrence of phthalic acid esters in soils and vegetables from green food and organic vegetable fields. J Anhui Agric Sci 38:10189-10191 (in Chinese)

Liu LP, Bao HQ, Liu F, Zhang J, Shen HQ (2012a) Phthalates exposure of Chinese reproductive age couples and its effect on male semen quality, a primary study. Environ Int 42:78-83

Liu SJ, Fang CG, Li Q, Jiang N, Yang DP (2012b) Monitoring and analysis of residues of phthalate esters in food in Jilin province. Chin J Health Lab Technol 3:68-71 (in Chinese)

Liu H, Cui KY, Zeng F, Chen LX, Cheng YT, Li HR, Li SC, Zhou X, Zhu F, Ouyang GF, Luan TG, Zeng ZX (2014) Occurrence and distribution of phthalate esters in riverine sediments from the Pearl River Delta region, South China. Mar Pollut Bull 83:358-365. doi:10. 1016/j.marpolbul.2014.03.038\#doilink

Lu RK (1999) Soil Science Society of China. Analysis methods of soil agricultural chemicals. Science and technology of China press, Beijing

Ma TT (2012b) Current pollution status, environmental risk assessment and bio-remediation of representative phthalate esters in farmland soil of typical facility agricultural regions. Dissertation, University of Chinese Academy of Sciences

Ma TT, Luo YM, Christie P, Teng Y, Liu WX (2012) Removal of phthalic esters in contaminated soil by different cropping systems: a field study. Eur J Soil Biol 50:76-82

Ma TT, Teng Y, Christie P, Luo YM, Chen YS, Ye M, Huang YJ (2013) A new procedure combining GC-MS with accelerated solvent extraction for the analysis of phthalic acid esters in contaminated soils. Front Environ Sci Eng 7:31-42

Masood F, Malik A (2013) Mutagenicity and genotoxicity assessment of industrial wastewaters. Environ Sci Pollut Res 20:7386-7397

Mikula P, Svobodová Z, Smutná M (2005) Phthalates: toxicology and food safety - a review. Czech J Food Sci 23:217-223

Mo CH, Cai QY, Tang SR, Zeng QY, Wu QT (2009) Polycyclic aromatic hydrocarbons and phthalic acid esters in vegetables from nine farms of the Pearl River Delta, South China. Arch Environ Contam Toxicol 56:181-189 
New York Department of Environmental Conservation (1994) Determination of soil cleanup objectives and cleanup levels. New York.

Ni YW, Ou ZQ (2000) Preferential flow and contamination preferential migration in soil: a review. Soil Environ Sci 9:60-63

NMED (New Mexico Environment Department) (2009) Technical background document for development of soil screening levels.

Overcash MR, Weber JB, Miles ML (1982) Behavior of organic priority pollutants in the terrestrial system: di-n-butyl phthalate ester, toluene, and 2,4 dinitrophenol. Water Resources Research Institute of the University of North Carolina.

Pang JM, Duan YL, Chi BL, Fan XW (1995) Residual and toxic analysis of DEHP in soil and Chinese cabbage. Chin Environ Chem 14:239 242 (in Chinese)

Pei XQ, Song M, Guo M, Mo FF, Shen XY (2013) Concentration and risk assessment of phthalates present in indoor air from newly decorated apartments. Atmos Environ 68:17-23

Pradeep S, Benjamin S (2012) Mycelial fungi completely remediate di (2ethylhexyl) phthalate, the hazardous plasticizer in PVC blood storage bag. J Hazard Mater. (235-236):69-77.

Romero-Franco M, Hernández-Ramírez RU, Calafat AM, Cebrián ME, Needham LL, Teitelbaum S, Wolff MS, López-Carrillo L (2011) Personal care product use and urinary levels of phthalate metabolites in Mexican women. Environ Int 37(5):867-871

Shen L, Xia B, Dai X (2013) Residues of persistent organic pollutants in frequently-consumed vegetables and assessment of human health risk based on consumption of vegetables in Huizhou, South China. Chemosphere 93:2254-2263

Shi W, Zhang FX, Hu GJ, Hao YQ, Zhang XW, Liu HL, Wei S, Wang XR, Giesy JP, Yu HX (2012) Thyroid hormone disrupting activities associated with phthalate esters in water sources from Yangtze River Delta. Environ Int 42:117-123

Sioen I, Fierens T, Van Holderbeke M, Geerts L, Bellemans M, De Maeyer M, Servaes K, Vanermen G, Boon PE, De Henauw S (2012) Phthalates dietary exposure and food sources for Belgian preschool children and adults. Environ Int 48:102-108

Tai YP, Mo CH, Wu XL, Li YW, Wang JY, Su QY, Huang PX (2011) Occurrence of quinolone antibiotics in soils from vegetable fields of Dongguan City. J Environ Sci 31:839-845

Teil MJ, Tlili K, Blanchard M, Chevreuil M, Alliot F, Labadie P (2012) Occurrence of polybrominated diphenyl ethers, polychlorinated biphenyls, and phthalates in freshwater fish from the orge river (Ile-de France). Arch Environ Contam Toxicol 63:101-113

USEPA (1996) Proposed guidelines for carcinogen risk assessment. Washington, DC, pp 17960-18011.

Wang LX, Kou LJ, Pan FY, Wang ML (2007) Determination of phthalates in vegetables by liquid chromatography electrospray ionization mass spectrometry with matrix solid phase dispersion. Chin $\mathrm{J}$ Anal Chem 35:1559-1564

Wolfe NL, Burns LA, Steen WC (1980) Use of linear free energy relationships and an evaluative model to assess the fate and transport of phthalate esters in the aquatic environment. Chemosphere 9: 393-402

Wu R, Niu MF, Guo Y, Wang J, Zhao MQ, Shi Y, Liu ZY (2009) Survey and analysis of pesticide contamination in greenhouse. J AgroEnviron Sci 28:130-134

Wu XL, Liang RX, Dai QY, Jin DC, Wang YY, Chao WL (2010) Complete degradation of di-n-octyl phthalate by biochemical cooperation between Gordonia sp. strain JDC-2 and Arthrobacter sp. strain JDC-32 isolated from activated sludge. J Hazard Mater 176: 262-268

Xu ZW, Cheng L, Shi J, Lu JG, Zhang WM, Zhao YL, Li FY, Chen MD (2014) Kinetic study of the removal of dimethyl phthalate from an aqueous solution using an anion exchange resin. Environ Sci Pollut Res 21:6571-6577

Yuan SY, Huang IC, Chang BV (2010) Biodegradation of dibutyl phthalate and di-(2-ethylhexyl) phthalate and microbial community changes in mangrove sediment. J Hazard Mater 184:826-831

Zhang LF, Dong L, Ren LJ, Shi SH, Zhou L, Zhang T, Huang YR (2012) Concentration and source identification of polycyclic aromatic hydrocarbons and phthalic acid esters in the surface water of the Yangtze River Delta, China. J Environ Sci 24:335-342

Zhang Q, Lu XM, Zhang XL, Sun YG, Zhu DM, Wang BL, Zhao RZ, Zhang ZD (2013) Levels of phthalate esters in settled house dust from urban dwellings with young children in Nanjing, China. Atmos Environ 69:258-264

Zhang Y, Tao Y, Sun GQ, Wang L (2014) Effects of di- $n$-butyl phthalate on the physiology and ultrastructure of cucumber seedling roots. Environ Sci Pollut Res 21:6662-6670

Ziogou K, Kirk PWW, Lester JN (1989) Behavior of phthalic acid esters during batch anaerobic digestion of sludge. Water Res 23:743-748 